\title{
Scale Economies of Pharmaceutical and Blockbuster R\&D in Japan with Possible Endogeneity and Dynamics
}

\author{
A. Fujii $^{\text {a }}$, T. Miyashige ${ }^{b}$ \\ ${ }^{a}$ Faculty of Economics and Business Administration, University of Kitakyushu, Fukuoka 802-8577, \\ Japan \\ ${ }^{\mathrm{b}}$ Advanced Course of International Business, Toyama National College of Technology, Toyama \\ 933-0293, Japan \\ Email: afujii@kitakyu-u.ac.jp
}

\begin{abstract}
This paper presents analysis of scale economies of R\&D efforts at the Japanese pharmaceutical companies, focusing on the blockbuster outputs with linear feedback mechanism. Comparing results of GMM estimation with previous studies implies: (i) The blockbuster development sub-process exhibits greater scale effect than in EU and US companies; (ii) The survival rate of blockbuster is a little higher in Japanese companies than in EU/US companies; (iii) The quantitative connection between patent research sub-process and blockbuster development sub-process is not significant.
\end{abstract}

Keywords: Blockbuster, patent, pharmaceutical R\&D, count data, linear feedback model 


\section{INTRODUCTION}

This article describes an empirical examination of scale economies of pharmaceutical $R \& D$ processes in Japan, with consideration of possible endogeneity of R\&D investment.

Previous studies of the pharmaceutical R\&D are classifiable into four categories based on R\&D performance measurements. Gambardella (1992), Henderson and Cockburn (1996), and Schwartzman (1976) considered the number of pharmaceutical patents. Graves and Langowitz (1993), Jensen (1987), and Odagiri and Murakami (1992) used the number of new chemical entities (NCEs). Comanor (1965), Schwartzman (1976), and Vernon and Gusen (1974) used a combination of the number of NCEs and the sales amount. Cockburn and Henderson (2001) used the number of approved new drugs.

Examination of the profitability of pharmaceutical R\&D, however, reveals that most of the profit for a pharmaceutical company apparently derives from selling only a few brands of new drugs (called blockbusters), as discussed in Miyashige (2008). According to Miyashige et al. (2007), where blockbusters were considered as an $R \& D$ performance index, the pharmaceutical $R \& D$ process can be divided into two sub-processes: A research process to produce patents of NCEs and a development process to develop these patents to approved final products as medical drugs. From this perspective, we can say that the previous studies described above - except for that of Cockburn and Henderson (2001) — analyzed the research sub-process only, rather than the development sub-process, the latter is more important for management of profit-seeking pharmaceutical companies. Consequently, analysis of firm-level blockbuster data as a pharmaceutical R\&D performance index has certain importance in understanding the economic aspect of pharmaceutical innovative technology.

The analysis of blockbusters requires statistical methods for count data because the number of blockbusters that one pharmaceutical company sells rarely exceeds ten. In fact, Miyashige et al. (2007) used a simple Poisson regression to conduct analyses on the data of the pharmaceutical companies in Europe and the United States. Many studies have been developed to date in the field of econometrics of count data, especially in treating endogenous or predetermined regressors in dynamic count data models: Montalvo (1997), Crépon and Duguet (1997), Blundell et al. (1995), and Blundell et al. (2002), to name but a few. Their results suggest usable moment conditions to estimate dynamic count data model in the generalized method of moment (GMM) framework. The endogeneity and predetermined nature of the regressors are problems of intertemporal correlation between the error terms and the regressors, which engender inconsistent estimation of parameters. These problems might be the case in pharmaceutical R\&D because the success (or the prospect of success) of creating a new drug may well alter the R\&D investment schedule. Abdelmoula and Bresson (2008) applied these GMM studies to the series of patent data of European regions with incorporation of the linear feedback model (LFM), which has its foundation in the integer-valued autoregressive (INAR) process proposed by Al-Osh and Alzaid (1987).

On the blockbuster R\&D, Fujii and Miyashige (2009) applied Abdelmoula and Bresson (2008)'s formulation to estimate the production function for the pharmaceutical companies in Europe and the United States. They found that (i) the blockbuster production shows nearly constant returns to scale, (ii) the quantitative connection between the blockbuster development sub-process and the patent research subprocess is weak, and (iii) the possibility of endogenous regressors problem is limited. Their results are similar to those of Miyashige et al. (2007), partly suggesting the validity of parametric Poisson modeling in Miyashige et al. (2007). On the other hand, the analysis on the blockbuster production by the Japanese pharmaceutical companies, which are the second major providers in the world drug market, is done by Miyashige and Fujii (2010) with the parametric Poisson model. They obtained a similar result as in Miyashige et al. (2007) and Fujii and Miyashige (2009), despite of the difference in the domestic market environments between the regions.

This paper reconsiders the pharmaceutical blockbuster R\&D analysis conducted in Miyashige and Fujii (2010) to compare the results from Fujii and Miyashige (2009). That is, we attempt to identify the scale economy parameter and patent effect parameter in blockbuster production by explicitly considering the problem of predetermined or endogenous regressors and verify the validity of parametric assumption in Miyashige and Fujii (2010). 


\section{MODEL AND DATA}

We formulate the quantity of blockbusters following Fujii and Miyashige (2009): ${ }^{1}$

$$
\mathbb{E}\left(B_{i t} \mid W_{i t}\right)=\beta_{B} B_{i, t-1}+\exp \left(\alpha_{0}+\alpha_{1} t+\alpha_{2} t^{2}+\beta_{R} \log R_{i t}+\beta_{P} \log P_{i, t-1}\right) .
$$

The symbols are defined as follows. $P_{i t}$ signifies the number of patents newly acquired by the pharmaceutical company $i$ during time period $t . R_{i t}$ denotes the annual total R\&D expense of the company. $B_{i t}$ stands for the number of blockbuster brands sold by the company. $\alpha_{0}, \alpha_{i}, \beta_{R}, \beta_{P}, \alpha_{1}$, and $\alpha_{2}$ are parameters. $W_{i t}$ represents the set of instrumental variables to be explained later.

The second term of (1) shows that the number of newly developed blockbusters is a function of the outcome of the research process in the preceding period $P_{i, t-1}$ and contemporaneous R\&D expense $R_{i t}$. The first term of the equation stands for the surviving blockbuster brands from the preceding period. This is a characteristic feature of a linear feedback model. The presence of this term introduces dynamics in the model and alleviates the collinearity which arises from the inclusion of many lag terms $R_{i, t-j}$. Because the number of blockbusters is typically a count data (the maximum in our data is 4 ), the sum of these two terms constitutes the conditional expectation that must be non-negative by definition.

The set of instrumental variables $W_{i t}$ depends on whether we assume the regressors are exogenous, predetermined, or endogenous. The set consists of regressors at any period if they are strictly exogenous; contemporaneous and past values of the regressors if they are predetermined; and contemporaneous values only if they are endogenous. Using a limited sample size, we attempt to use the following simple settings for instruments: Let $W_{i t}^{\text {end }}=\left\{\log R_{i t}, \log P_{i, t-1}, B_{i, t-1}\right.$, (firm dummies), (time trend), (time trend) $\left.{ }^{2}\right\}$ for endogenous-regressors assumption; $W_{i t}^{\text {prd }}=W_{i t}^{\text {end }} \cup\left\{\log R_{i, t-1}\right\}$ for predetermined-regressors assumption; $W_{i t}^{\text {exg }}=W_{i t}^{\text {prd }} \cup\left\{\log R_{i, t+1}\right\}$ for strictly exogenous assumption.

Our data were collected from several sources. For the number of blockbusters $\left(B_{i t}\right)$ was collected from Monthly Mix Magazine (Elsevier Japan, 1996-2009). Blockbusters with an annual sale exceeding 30 billion yen were examined. The R\&D investment $\left(R_{i t}\right)$ in million yens and the number of patents $\left(P_{i t}\right.$, international classification A61K in Japan) were obtained from DATABOOK (1996-2009) published by Japan Pharmaceutical Manufacturers Association (JPMA). After eliminating observations which lack necessary data, we obtained 116 observations for 21 Japanese pharmaceutical companies. Sample years range from 1996 to 2006. $R_{i t}$ is adjusted to real term as of 1997 by GDP deflator. The descriptive statistics of the data described above are shown in Table 1.

Table 1. Descriptive statistics

\begin{tabular}{lrrrr}
\hline Variable & Mean & Std. Dev. & Min. & \multicolumn{1}{c}{ Max. } \\
\hline$B_{i t}$, number of blockbusters & 1.05 & 1.12 & 0 & 4 \\
$R_{i t}$, R\&D investment & 42129.18 & 29250.25 & 6144 & 153020 \\
$P_{i t}$, number of patents & 46.41 & 36.32 & 6 & 206 \\
\hline
\end{tabular}

Note: $R_{i t}$ is in million yens as of 1997.

\section{EMPIRICAL RESULTS}

In Table 2, we report the results of GMM estimation of equation (1), for various exogeneity assumptions on the regressors.

The estimates of the slope parameters are similar across the models (the difference between the models are less than 10\% relative to the average of three models). The Sargan test p-values are also similar across the models. In this sense, the possibility of endogenous regressor problems is limited in the Japanese blockbuster R\&D.

${ }^{1}$ We estimated a model in which $\alpha_{0}$ varies across the firms, by having it be a function of the earliest observation on $R_{i t}$ and $P_{i t}$. However, we found the coefficients of these variables in the $\alpha_{0}$ equation are not statistically significant. 
Table 2. GMM estimation result

\begin{tabular}{lrrr}
\hline Parameter & Endogenous & Predetermined & Exogenous \\
\hline$\alpha_{0}$ & -11.510 & -11.643 & -11.731 \\
& 4.216 & 4.267 & 4.207 \\
\hline$\alpha_{1}$ & -0.023 & -0.031 & -0.062 \\
& 0.287 & 0.286 & 0.276 \\
\hline$\alpha_{2}$ & 0.002 & 0.003 & 0.005 \\
& 0.019 & 0.019 & 0.018 \\
\hline$\beta_{B}$ & 0.836 & 0.836 & 0.832 \\
& 0.056 & 0.056 & 0.055 \\
\hline$\beta_{R}$ & 1.017 & 1.038 & 1.061 \\
& 0.456 & 0.461 & 0.454 \\
\hline$\beta_{P}$ & -0.176 & -0.190 & -0.209 \\
& 0.280 & 0.280 & 0.275 \\
\hline Sargan & 24.488 & 24.981 & 26.080 \\
(p-value) & 0.222 & 0.248 & 0.248 \\
d.f. & 20 & 21 & 22 \\
\hline Note: Standard errors are shown below parameter estimates
\end{tabular}

Note: Standard errors are shown below parameter estimates.

The scale economies of blockbuster development, $\beta_{R}$ is estimated 1.02-1.06, with standard errors being $0.45-0.46$. Though the relatively large standard errors in this study leave us unsure of the exact returns to scale, the confidence interval nearly stays rightward of that for European and US companies (Fujii and Miyashige, 2009). This is same as what we observed in the comparison of European/US and Japanese companies with Poisson regression analyses (Miyashige et al., 2007; Miyashige and Fujii, 2010). In this sense, the blockbuster production seems to exhibit more scale effect in Japan than in Europe and US. This finding implies the scale economies does not contradict the fact some M\&A cases have arisen with the world's leading pharmaceutical companies, not only in European/US regions.

Regarding the R\&D sub-process dynamics modeled as linear feedback in blockbuster development, $\beta_{B}$ is approximately 0.84 . As with other LFM specifications, $\beta_{B}$ can be interpreted easily that $1-\beta_{B}=16 \%$ of blockbuster brands on average disappear each period, possibly through reduction in their sales. This is higher than 0.6 or 0.7 for European/US companies. Japanese patients, or physicians as agents of patients, prefer the new (branded) drugs to the generic products even after the expiration of new drugs' patents. The higher $\beta_{B}$ in Japan can be interpreted as the reflection of this preference.

We may assess the effect of holding more patents on the number of blockbusters by the elasticity of blockbuster with respect to patent, $\beta_{P}$. Our estimates are not statistically significant. This result is same as in Miyashige and Fujii (2010). For the European/US companies, Miyashige et al. (2007) and Fujii and Miyashige (2009) observed that the parameter estimates are statistically significant but smaller than $\beta_{R}$. These two facts suggest limited effect of patents on blockbusters in any of the regions. In other words, it is preferable to separate research sub-process of patents and development sub-process of blockbusters in the analysis of whole pharmaceutical R\&D. In Europe, US, or in Japan, pharmaceutical companies used to do in-house development, in which they try to raise the candidates created by the research section of the own company to the final product. In recent years, however, they tend to switch to license-in strategy, in which they "buy candidates" created by other ventures. The studies on European/US companies by Miyashige et al. (2007) and Fujii and Miyashige (2009) are based on data periods from 1992 to 2003, while ours and Miyashige and Fujii (2010) are based on periods from 1995 to 2007. The difference in the estimates or significance between Japan and other areas may partly be due to the license-in tendency and the difference in the sample periods. 


\section{CONCLUSIONS}

Our results of blockbuster production equation, combined with previous studies on the same topic, can be summarized as follows. (i) The blockbuster development sub-process does not show diseconomies of scale, which is consistent with the fact of global mergers. (ii) The survival rate of existing blockbusters over a year in Japan is a little higher than in world major markets. (iii) The quantitative connection between patent research sub-process and blockbuster development sub-process measured by elasticity of the blockbusters is insignificant, regardless of regions and dynamics specification.

These results contrasted with those of previous studies in the following points: Although previous studies demonstrated diseconomies of scale in pharmaceutical R\&D, we can come to different conclusions if we replace the R\&D outcome index with blockbusters, which are directly important to for-profit companies. This finding is very useful for considering series of M\&A activities that have taken place among the world's big pharmaceutical companies.

Future research should enhance the sample to include other pharmaceutical companies that have a shorter history of data or which have been involved in any M\&A, by explicitly incorporating into the model the synergy effects attributable to M\&A. Another important topic is the analysis of biochemical industries in terms of blockbuster productivity. Recent new drug R\&Ds often use monoclonal antibodies. Their associated R\&D processes, which are done in biochemical industries, have different features from those of conventional chemical synthesis basis. Therefore, the future market structure of new drugs will depend also on the R\&D structure of biochemical firms.

\section{ACKNOWLEDGEMENT}

This work was supported by Grant-in-Aid for Scientific Research (C) from Japan Society for the Promotion of Science (No. 21530430).

\section{REFERENCES}

Abdelmoula, M. and G. Bresson (2008). Spatial and technological spillovers in european patenting activities: A dynamic count panel data model. Annals of Economics and Statistics 87/88, 167-194.

Al-Osh, M. A. and A. A. Alzaid (1987). First-order integer valued autoregressive (inar(1)) process. Journal of Time Series Analysis 8, 261-275.

Blundell, R., R. Griffith, and J. V. Reenen (1995). Dynamic count data models of technological innovation. The Economic Journal 105(429), 333-344.

Blundell, R., R. Griffith, and F. Windmeijer (2002). Individual effects and dynamics in count data models. Journal of Econometrics 108, 113-131.

Cockburn, I. M. and R. M. Henderson (2001). Scale and scope in drug development: unpacking the advantages of size in pharmaceutical research. Journal of Health Economics 20, 1033-1057.

Comanor, W. S. (1965). Research and technical change in the pharmaceutical industry. Review of Economics and Statistics 47, 182-190.

Crépon, B. and E. Duguet (1997). Estimating the innovation function from patent numbers: GMM on count panel data. Journal of Applied Econometrics 12, 243-263.

Fujii, A. and T. Miyashige (2009). Scale economies of pharmaceutical patent and blockbuster R\&D with possible endogeneity and dynamics. In R. S. Anderssen, R. Braddock, and L. Newham (Eds.), 18th World IMACS Congress and MODSIM09 International Congress on Modelling and Simulation, pp. 1113-1118. Modelling and Simulation Society of Australia and New Zealand and International Association for Mathematics and Computers in Simulation.

Gambardella, A. (1992). Competitive advantages from in-house scientific research: the US pharmaceutical industry in the 1980s. Research Policy 2, 391-407. 
A. Fujii and T. Miyashige, Scale economies of pharmaceutical and blockbuster R\&D in Japan...

Graves, S. B. and N. S. Langowitz (1993). Innovative productivity and returns to scale in the pharmaceutical industry. Strategic Management Journal 14, 593-605.

Henderson, R. and I. Cockburn (1996). Scale, scope and spillovers: the determinants of research productivity in drug discovery. RAND Journal of Economics 27, 32-59.

Jensen, E. J. (1987). Research expenditures and the discovery of new drugs. Journal of Industrial Economics 36, 83-95.

Miyashige, T. (2008). Analysis of the "effective" $R \& D$ that contributes profit: decomposition into research and development processes ("Shueki Ni Koken Suru Kenkyukaihatsuseika Ni Oyobosu Kenkyukaihatsutoshikoka No Kenkyu” in Japanese). Ph. D. thesis, Kanazawa University, The Graduate School of Natural Science and Technology.

Miyashige, T. and A. Fujii (2010). Are research and development processes independent in the Japanese pharmaceutical R\&D? In Electronic Proceedings, pp. 245-249. The 14th World Multi-Conference on Systemics, Cybernetics and Informations (WMSCI) 2010.

Miyashige, T., A. Fujii, and K. Kimura (2007). Are research and development processes independent in the pharmaceutical R\&D? In L. Oxley and D. Kulasiri (Eds.), MODSIM 2007 International Congress on Modelling and Simulation, pp. 74-80. Modelling and Simulation Society of Australia and New Zealand.

Montalvo, J. G. (1997). GMM estimation of count-panel-data models with fixed effects and predetermined instruments. Journal of Business and Economic Statistics 15(1), 82-89.

Odagiri, H. and N. Murakami (1992). Private and quasi-social rates of return on pharmaceutical R\&D in japan. Research Policy 21, 335-345.

Schwartzman, D. (1976). Innovation in the Pharmaceutical Industry. Baltimore: Johns Hopkins University Press.

Vernon, J. M. and P. Gusen (1974). Technical change and firm size: the pharmaceutical industry. Review of Economics and Statistics 56, 294-302. 